\title{
kWh Demand Assessment and Forecasting of a Low Voltage Private Academic Institution
}

\author{
Joy R. Antonio, Antonio S. Buendia Jr., Gina B. Narca, Noel T. Florencondia, Lorinda Pascual
}

\begin{abstract}
Transformer is one of the crucial components in an electrical system. They are used to convert energy to a utilization level. Load allocation is vital to sustaining the needed energy demand for a growing population, and it is an essential consideration for continuous consumer connectivity of electricity. In this study, the researchers are conducting assessment and forecast of the transformer requirement for a Low Voltage Private Academic Institution. It assessed the kWh demands and kWh allocation from 2005 to 2019 of the three transformers used of the locale. The $\mathrm{kWh}$ demand was used to forecast the per semiannual for the next five years. Six forecasted models were applied and the result were verified by $Q M$ for Windows Version 5. Mean Absolute Error (MAE), Mean Square Error (MSE) and Mean Absolute Percent Error (MAPE) were used to select the best forecasting model with the least value. DT (Distribution Transformer) 1 used the $4^{\text {th }}$ degree polynomial model because of the least value of MAE, MSE and MAPE of 5340.626, 42306100 and $17.12 \%$, while DT 2 and DT 3 applied the $3^{\text {rd }}$ degree polynomial model though it has the second lowest value of MAE, MSE and MAPE of 3142.907, 16748570, 20.44\% and 2576.398, $8740315,11.21 \%$ respectively because the projected demand of the $4^{\text {th }}$ degree gave a negative value.. The researcher finds that DT 1 and 3 were starting to exceeds the allotted $k W h$. On the other hand, DT 2 and 4 were plenty of $k W h$ allocation. Relocation of load from DT 1 and 3 to DT 2 may take for considerations by the institution.
\end{abstract}

Keywords: Distribution Transformer), $k W h$ Demand, $k W h$ allocation, Forecasting.

\section{INTRODUCTION}

Transformers were widely used in an electrical power system, whether in the generation system, transmission system and distribution system. Transformers function is to transform energy to usable level to utilize by people. In a distribution power system, distribution transformers were usually installed in an operating range of 13,800 primary voltage input to a secondary output voltage of 230 volts. Transformers in the distribution system are classified to be either:

Manuscript received on January 12, 2021.

Revised Manuscript received on April 10, 2021.

Manuscript published on April 30, 2021.

* Correspondence Author

Joy R. Antonio*, Degree, Nueva Ecija University of Science and Technology, Philippines.

Antonio S. Buendia Jr., Pursued Electrical Engineering, Asiathe Nueva Ecija University of Science and Technology, Philippines.

Gina B. Narca, Professional Philippine Rice Research Institute, Central Experiment Station located at Maligaya, Science City of Munoz, Nueva Ecija, Philippines.

Noel T. Florencondia, Dean, College of Engineering, Nueva Ecija University of Science and Technology,

Lorinda Pascual, Professor, Nueva University of Science and Technology. Philippines.

(C) The Authors. Published by Blue Eyes Intelligence Engineering and Sciences Publication (BEIESP). This is an open access article under the CC BY-NC-ND license (http://creativecommons.org/licenses/by-nc-nd/4.0/) (a). sole-user distribution transformer (if only one consumer entity uses one kWh meter like industrial, commercial, public building) and

(b). commonly-used distribution transformer (if multiple consumers or multiple $\mathrm{kWh}$ meters are installed like in most residential areas).

Categorization Sole-user according to the connection of the electric meter.

i. High Voltage if the meter is connected in the primary side of the transformer and also called primary meter.

ii. Low Voltage if the meter is connected in the secondary side of the transformer and also called secondary meter.

Distribution transformer rating is measured in $\mathrm{kVA}$, commonly installed in the distribution system were $10 \mathrm{kVA}$, $15 \mathrm{kVA}, 25 \mathrm{kVA}, 37.5 \mathrm{kVA}, 50 \mathrm{kVA}$. For a transformer, loading capacity is vital for consumer connectivity of electricity. Maximum capacity of it must be $70 \%$ [1]. With this, loading of transformer must be taken into account to prevent transformer failure due to exceeding its normal loading [2-3]. About $50 \%$ of its useful life is affected when exceeding of normal loading occurs [4], while on the other hand, in below normal loading of transformers do not utilize its use and contribute more core loss [5]. To ensure transformer-costumer connectivity it must be taken to account an effective transformer load monitoring system and transformer data such as rating, connection, and location. [6].

Energy management must show consumers demand and allocation accurately, to inform the consumer about the details of their actual energy usage. [7]. In the recent years, due to the increasing demand of electricity, most of the consumer in distribution utility were driven to improve energy loading management, one of which is academic institution. In Bohol Island State University-Main Campus applied the used of solar power. [8]. Due the increasing number of students, Don Honorio Ventura State University projected the available electric source it can provide. [9]. Computer simulated-audit and analyzed the $\mathrm{kWh}$ consumption of each room were conducted by Pamantasan ng Lunsod ng Maynila [10].

Electrical load forecasting has different types, namely:

(a) very-short term forecasting uses few minutes to an hour,

(b) short term forecasting uses a day or a week prediction,

(c) medium-term forecasting is applicable if the prediction within 2 weeks to 3 years range and

(d) long term electrical load forecasting must be taken to account if the forecast interval from 3 years to 50 years, 


\section{kWh Demand Assessment and Forecasting of a Low Voltage Private Academic Institution}

Demand for electricity is evidently increase, and this is affecting the loading condition of the transformer.

To give awareness of the needs of the consumers conducting for an assessment the present loading conditions is vital. And forecasting of electrical energy demand can help in determining if the capacity can carry the demand needed. To reduce uncertainties,

planning for additional sources and to the prediction of the phase of electric power must be taken to account [11]. The objective of the study is to assess the present and future loadings of the transformer of low voltage private academic institution. Specifically, the study tends in determining the electrical loading and allocation of each transformer per semi-annual per year and to analyze the historical loading trends. The results are intended to be applied to forecast the percent loading per semi-annual for the next five years.

\section{Locale of the Study}

The locale of the study is a private academic institution founded in 1945.

It offers different programs such as graduate studies, college, junior high school, senior high school and elementary. From 2005 to 2015 the total student enrolled in the institution were less than 2000 until the year 2016, when the institution starts to offer senior high school program, the number of enrolled students increased as shown in Figure 1. In the academic year 2016-2017, an increase of $44.67 \%$ of enrolled student had experienced.

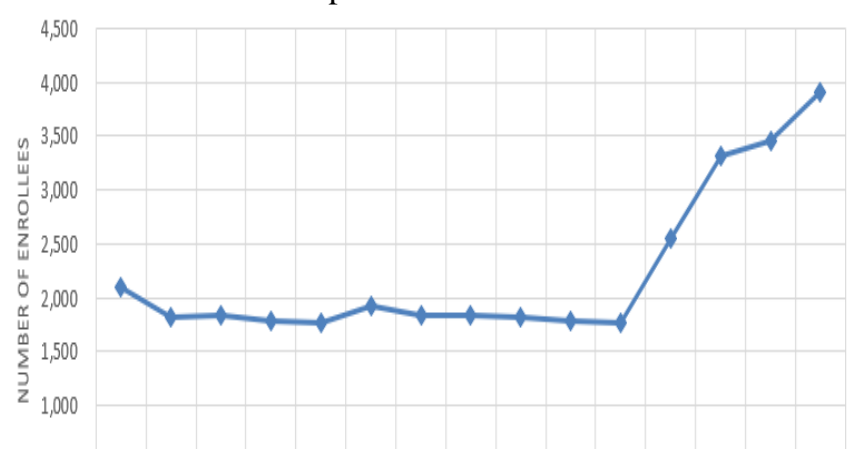

500

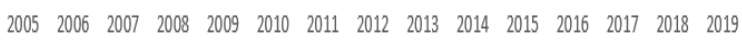
YEAR

Figure1: Number of Enrolled Student (2005 - 2019)

\section{Load Demand of the locale}

Three (3) distribution transformers installed around the campus with kVA ratings of 15kVA (DT 1), 3 units of 25 kVA (DT 2) and 10 kVA (DT3). From 2005, DT 1 and 2 are being used, and in 2014, DT 3 was installed to cater the increase of energy demand in preparation for the offering of $\mathrm{K}-12$ program. The annual kWh demand is shown in Figure 2. The figure shows that the $\mathrm{kWh}$ demand in 2016 of the institution started to increase due to the addition of students enrolled. In academic 2015 - 2016, the energy demand rose to $14.19 \%$ in the same way the energy consumption amounting to $\mathrm{P} 1,258,679.84$. In 2017 - 2018, 22.93\% increase for compare in the last academic year. It is undeniable that the demand increased.

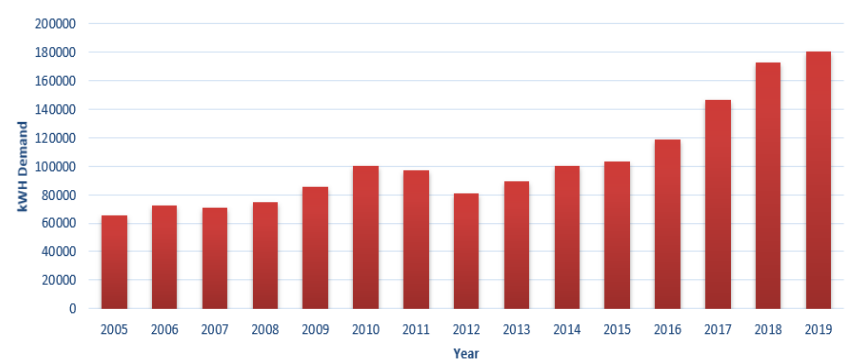

Figure 2: Yearly kWh Demand

\section{Individual Load Profiling of Transformers}

In Figures 3 - 5 show the individual semi-annual kWh demand of each transformer installed in the institution. DT 1 and 2 shows an increasing trend; in the year 2016, when the k-12 programs were offered, the demand increased, each has demand value of 46,545 $\mathrm{kWh}$ and 24,150 kWh respectively. It is observable that the $\mathrm{kWh}$ demand has continually increased on the next academic years, as seen in Figures 3 and 4 . On the other hand, there is a time in which the graph showed a decrease in usage, which is the first half of the year during April and May vacation period when minimal energy is consumed.

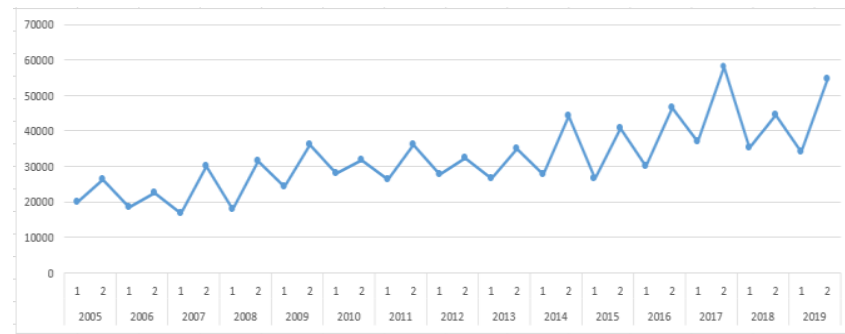

Figure 3: DT 1 Semi-Annual kWh Demand

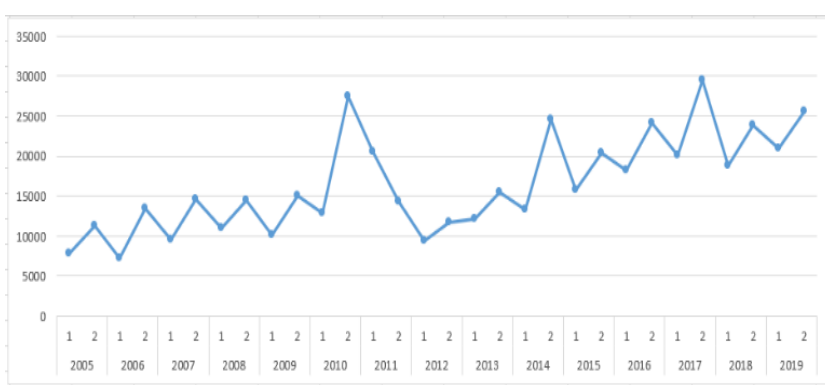

Figure 4: DT 2 Semi-Annual kWh Demand

For the preparation of the offering of the k-12 programs, DT 3 was installed in the year 2014. As the school-year 2016-2017 came, there is an escalating demand experienced as revealed in Figure 5, energy demand for 55,640 kWh for that year. And for the succeeding years, the energy demand is still increasing.

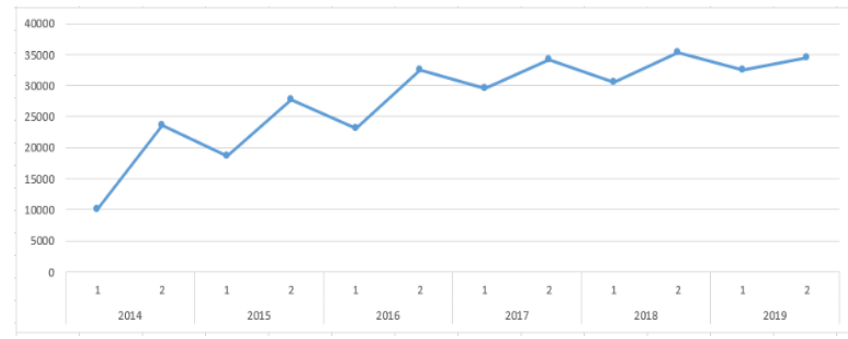

Figure 5: DT 3 Semi-Annual kWh Demand

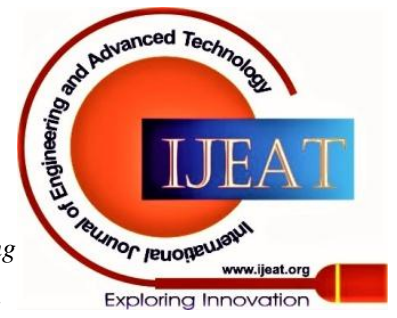


Forecasting will be performed in the study using the historical energy consumption of the present system to assess the kWh demand. Buildings connected to each meter was not considered in the study since it requires legal coordination with the utility. Hence, the researcher focused on the loading of the transformer installed in the institution to identify the loading condition of each transformer. This will give awareness and information on the utilization of the transformer to the administration of the institution.

\section{METHODOLOGY}

\section{A. Data Collection and Instrument}

Data needed in the study such as the kWh consumption per meter and $\mathrm{kWh}$ rating of each transformer installed were gathered from the electric utility. 2005 - 2019 kWh consumption and $\mathrm{kWh}$ ratings of transformers were the input parameters of the study; this will be used to evaluate the loading demand of the transformer, as shown in Figure 6. The researcher had used QM for Windows for the statistical treatment and Microsoft Excel 2016 for load demand forecast.

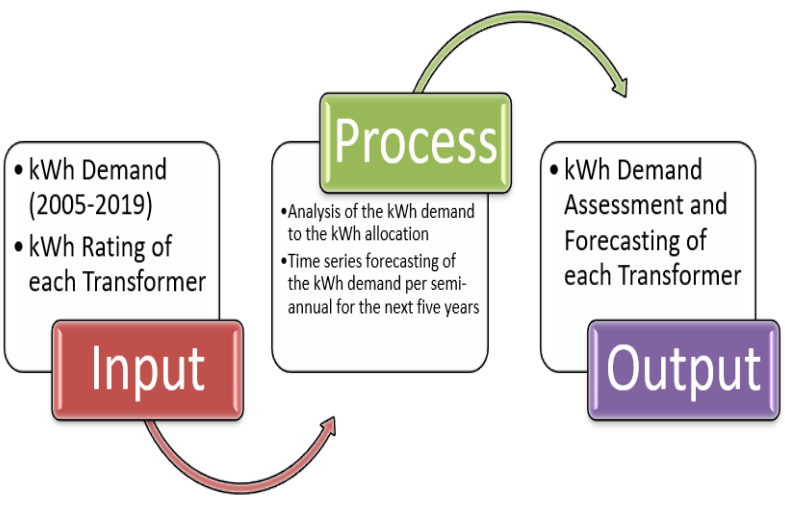

Figure 6: Conceptual Framework of the Study

\section{B. Assessment of Transformer}

From the data gathered from electrical utility, the three (3) distribution transformer and kWh consumption (2005 2019) were used to determine the $\mathrm{kWh}$ demand per semiannual of the transformer by using Microsoft Excel 2016.

\section{Forecasting}

The load demand values will be used to forecast the per semi-annual for the five (5) years ahead. The study is classified as long-term forecasting. Best loading values will be based for the forecast model. Forecasted data will be gathered using the mathematical forecasted model. The software to be used is QM for Windows for the statistical treatment to identify the Mean Absolute Error (MAE), Mean Squared Error (MSE) and Mean Absolute Percent Error (MAPE). The result will be a criterion to test the accuracy of the forecasted model.

1. Mean Absolute Error (MAE) - It is a measure of how close the forecasted value to the actual value [9], [12-13].

$$
\text { Where: } \begin{aligned}
M A E & =\frac{\left(\sum_{t=1}^{t=t}\left|A_{t}-F_{t}\right|\right)}{t} \\
\mathrm{~A}_{\mathrm{t}} & =\text { Actual Value } \\
\mathrm{F}_{\mathrm{t}} & =\text { Forecasted Value } \\
\mathrm{t} & =\text { time }
\end{aligned}
$$

2. Mean Square Error (MSE). It is always a positive value and it is closer to the value of zero the better [9], [12-13].

$$
\begin{aligned}
\text { Where: } \quad \begin{aligned}
t=t \\
\text { WhE }
\end{aligned} & =\frac{\left.\left(A_{t}-F_{t}\right)^{2}\right)}{t_{\mathrm{t}}}=\text { Actual Value } \\
\mathrm{F}_{\mathrm{t}} & =\text { Forecasted Value } \\
\mathrm{t} & =\text { time }
\end{aligned}
$$

3. Mean absolute Percent Error (MAPE). Is a measure of accuracy is expressed in percentage of the average of the absolute value of error [12-13].

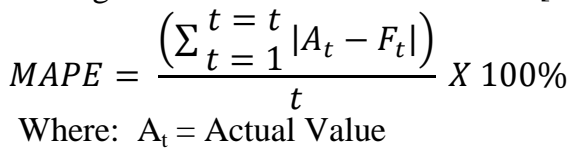

$$
\begin{aligned}
\mathrm{F}_{\mathrm{t}} & =\text { Forecasted Value } \\
\mathrm{t} & =\text { time }
\end{aligned}
$$

With this criterion, the forecasted model to be used must be the least value of MAE, MSE and MAPE [13-15].

\section{RESULTS \& DISCUSSION}

Two (2) sections were provided for the data presentation of the study. The first section is the load demand of each transformer installed in the institution and the assessment of the loading conditions. While the second section is the forecasting analysis of the kWh demand per semi-annual for the next five-years.

\section{A. Assessment of Transformer}

The graphical representation of the kWh demand of the transformers installed is shown in Figures 9-11. These data were taken to account to assess the $\mathrm{kWh}$ demand of the four (4) transformers. DT 1 in Figure 7 shows that its kWh demand exceeds the $\mathrm{kWh}$ allocation in the last half of year 2017 and 2019. In the academic year 2016-2017, the kWh demand of DT 1 started to reaches the maximum $\mathrm{kWh}$ allocation.

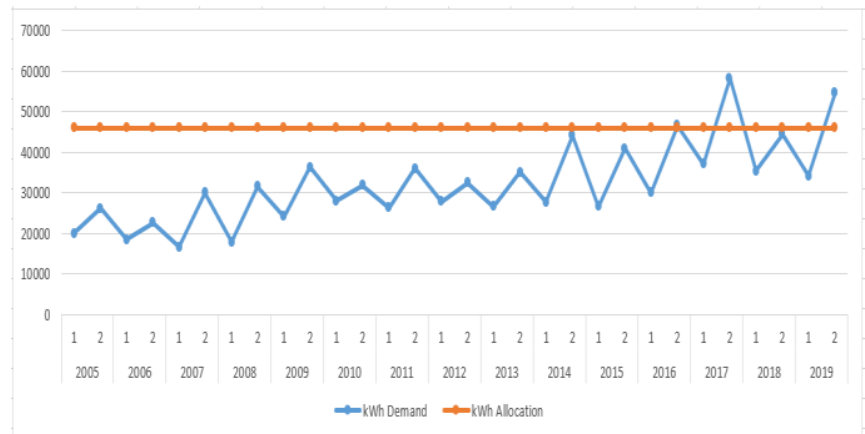

Figure 7: Loading Condition of DT 1

Figure 8 shows that DT 2's loading condition did not reach the $\mathrm{kWh}$ allocation. Although it reached to 29250 kWh for the last half of 2017, it can be observed that the gap between the kWh allocation and the kWh Demand is wider.

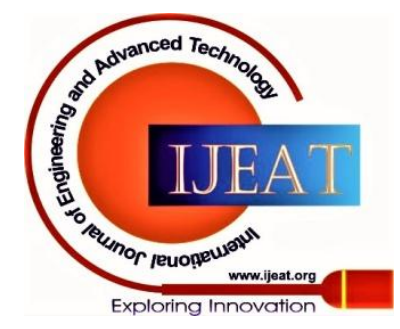


kWh Demand Assessment and Forecasting of a Low Voltage Private Academic Institution

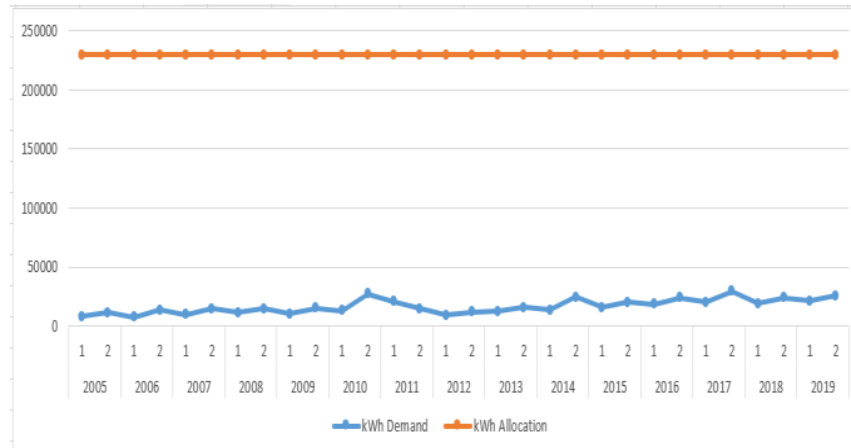

Figure 8: Loading Condition of DT 2

The kWh of DT 3 in Figure 9 shows nearly a normal loading condition. In the last half of 2016, the kWh demand reached the maximum $\mathrm{kWh}$ allocation. Starting 2017 the gap of the $\mathrm{kWh}$ demand and the $\mathrm{kWh}$ allocation became narrower as shown.

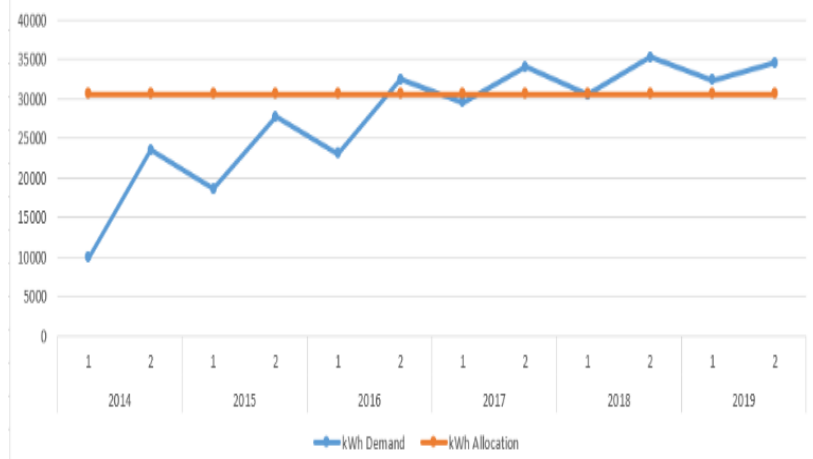

Figure 9: Loading Condition of DT 3

\section{B. Forecasting per semi-annaul for the next 5 years}

Six forecasting model was used for the transformers to test the best of fit of kWh demand shown in Table 1, 2, 3 and 4 , respectively. The chosen model is based on the values of the measure of accuracy which are Mean Average Error (MAE), Mean Square Error (MSE) and Mean Absolute Percent Error (MAPE) that were acquired using QM for Windows [14-15]. The lower the values of the MAE, MSE and MAPE the better the fit and useful of the forecasted model.

For DT 1 , the $4^{\text {th }}$ degree polynomial model had been chosen because it has the least value of MAE, MSE, and MAPE as seen in Table 1.

Table 1: Measure of Accuracy for DT 1

\begin{tabular}{|l|c|c|c|}
\hline \multirow{2}{*}{ Function } & \multicolumn{3}{|c|}{ Test of Accuracy } \\
\cline { 2 - 4 } & MAE & MSE & MAPE \\
\hline Linear & 5405.61 & 43260480 & $17.22 \%$ \\
\hline Exponential & 5425.468 & 43066730 & $17.13 \%$ \\
\hline Logarithmic & 6050.986 & 54448960 & $20.08 \%$ \\
\hline 2nd Degree Polynomial & 5412.667 & 42699600 & $17.34 \%$ \\
\hline 3rd Degree Polynomial & 5351.055 & 42309390 & $17.16 \%$ \\
\hline 4th Degree Polynomial & 5340.626 & 42306100 & $17.12 \%$ \\
\hline
\end{tabular}

The $4^{\text {th }}$ degree polynomial model for the semi-annual kWh demand from 2005 - 2019 is expressed as

$$
f(x)=a_{1} x^{4}+a_{2} x^{3}+a_{3} x^{2}+a_{4} x+a_{5}
$$

where

$$
\begin{aligned}
& \mathrm{a}_{1}=0.0166 \\
& \mathrm{a}_{2}=0.2074 \\
& \mathrm{a}_{3}=-25.46 \\
& \mathrm{a}_{4}=1092.8
\end{aligned}
$$

$$
\begin{aligned}
& \mathrm{a}_{5}=18897 \\
& \mathrm{x}=\text { number of semi-annuals }
\end{aligned}
$$

And the per semi-annual for the next five-years forecast using $4^{\text {th }}$ degree polynomial model was shown in Figure 10

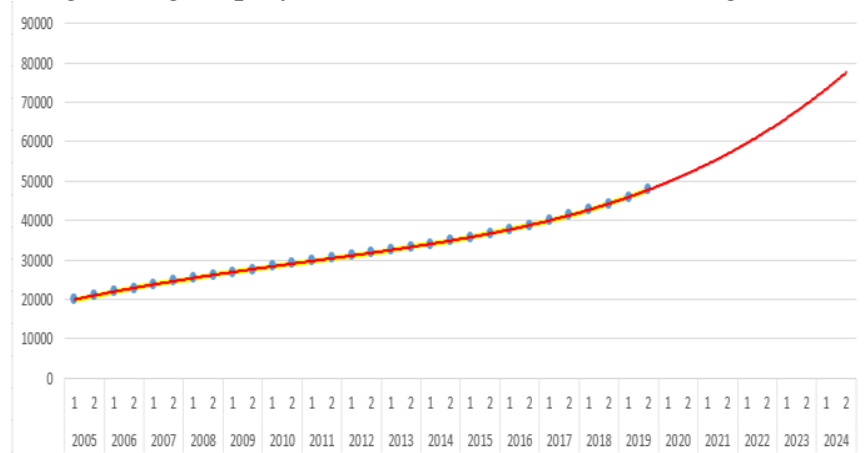

\section{Figure 10: DT 1 Semi-Annual $4^{\text {th }}$ degree Polynomial Model}

In the case of DT 2, $3^{\text {rd }}$ degree polynomial model was chosen second lowest value of MAE, MSE and MAPE compare for the $4^{\text {th }}$ degree polynomial model due to the forecasted values of $4^{\text {th }}$ degree polynomial was negative in values.

Table 2: Measure of Accuracy for DT 2

\begin{tabular}{|l|c|c|c|}
\hline \multirow{2}{*}{ Function } & \multicolumn{3}{|c|}{ Test of Accuracy } \\
\cline { 2 - 4 } & MAE & MSE & MAPE \\
\hline Linear & 3278.364 & 17183380 & $21.36 \%$ \\
\hline Exponential & 3128.823 & 17327910 & $19.76 \%$ \\
\hline Logarithmic & 3607.636 & 19834880 & $24.60 \%$ \\
\hline 2nd Degree Polynomial & 3234.395 & 17093690 & $21.12 \%$ \\
\hline 3rd Degree Polynomial & 3142.907 & 16748570 & $20.44 \%$ \\
\hline 4th Degree Polynomial & 3089.203 & 16264560 & $20.03 \%$ \\
\hline
\end{tabular}

For DT 2, the forecasted semi-annual was attained by using the $3^{\text {rd }}$ degree polynomial model

$$
f(x)=b_{1} x^{3}+b_{2} x^{2}+b_{3} x+b_{3}
$$

where

$$
\begin{aligned}
& b_{1}=1.1604 \\
& b_{2}=-49.48 \\
& b_{3}=1039.5 \\
& b_{4}=7575.2 \\
& x=\text { number of semi-annuals }
\end{aligned}
$$

The regression model of the $3^{\text {rd }}$ degree polynomial model in semi-annual in five-years ahead can be seen in Figure 11.

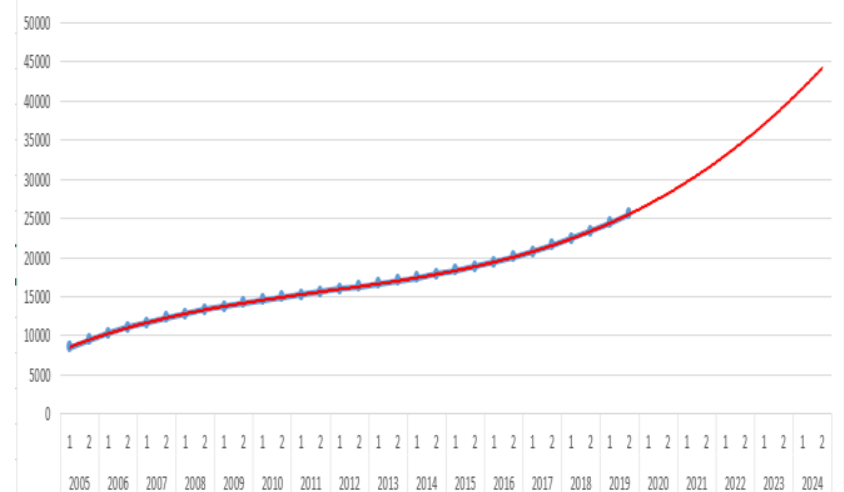

Figure 11: DT 2 Semi-Annual $3^{\text {rd }}$ degree Polynomial Model

Published By:

Blue Eyes Intelligence Engineering \& Sciences Publication

(C) Copyright: All Rights Reserved

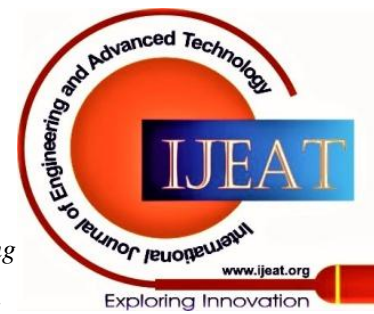


In Table 3, the lowest MAE, MSE and MAPE is the $4^{\text {th }}$ degree polynomial model. But the forecasted value just like what happen to DT 2, the values were negative. The next best model must be the $3^{\text {rd }}$ degree polynomial model which is the second lower value in MAE, MSE and MAPE.

Table 3: Measure of Accuracy for DT 3

\begin{tabular}{|l|c|c|c|}
\hline \multirow{2}{*}{ Function } & \multicolumn{3}{|c|}{ Test of Accuracy } \\
\cline { 2 - 4 } Linear & MAE & MSE & MAPE \\
\hline Exponential & 3392.816 & 15125570 & $16.26 \%$ \\
\hline Logarithmic & 3929.657 & 21564780 & $17.19 \%$ \\
\hline 2nd Degree Polynomial & 2596.677 & 8307616 & $11.04 \%$ \\
\hline 3rd Degree Polynomial & 2576.398 & 8740315 & $11.21 \%$ \\
\hline 4th Degree Polynomial & 2576.917 & 8495130 & $10.87 \%$ \\
\hline
\end{tabular}

For DT 3 the $3^{\text {rd }}$ degree polynomial model for the semiannual kWh demand is interpret as

$$
\begin{aligned}
& f(x)=c_{1} x^{3}+c_{2} x^{2}+c_{3} x+c_{4} \\
& \mathrm{c}_{1}=23.107 \\
& \mathrm{c}_{2}=-680.31 \\
& \mathrm{c}_{3}=7211.4 \\
& \mathrm{c}_{4}=5925.7 \\
& \mathrm{x}=\text { number of semi-annuals }
\end{aligned}
$$

And the semi-annual $\mathrm{kWh}$ demand in five-year ahead prediction using the $3^{\text {rd }}$ degree polynomial model can be seen in Figure 12.

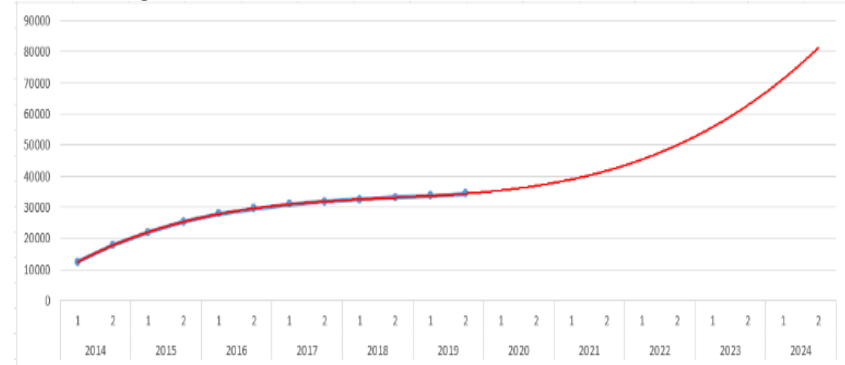

Figure 12: DT 3 Semi-Annual $3^{\text {rd }}$ Degree Polynomial Model

The administration must take into consideration is the gap between the kWh demand and kWh Allocation of the transformer for maximum utilization. The researcher has used the $4^{\text {th }}$ degree polynomial model to project the five (5) years ahead semi-annual kWh demand for DT 1 , as seen in Figure 13. The graph shows that the transformer will exceed the allocated kwh which will cause power failure in the long run.

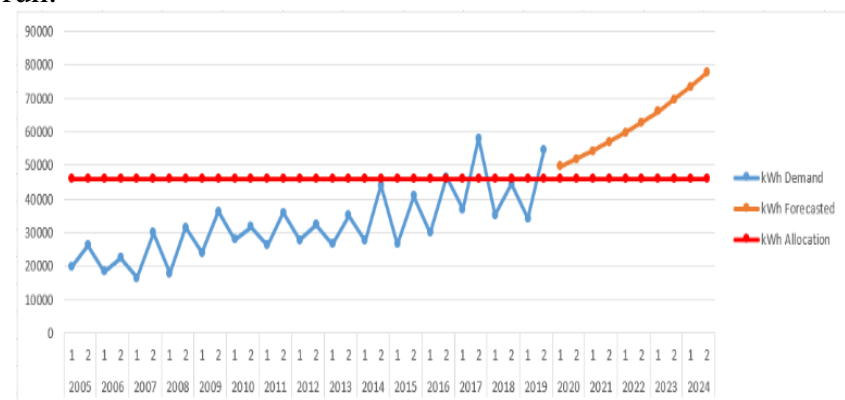

Figure 13: DT 1 kWh Demand, kWh Forecasted and kWh Allocation

In the case of DT 2 , the $3^{\text {rd }}$ degree polynomial model applied still there is a large gap between $\mathrm{kWh}$ demand before it can reach the $\mathrm{kWh}$ allocation as seen in Figure14. Even in the forecasted per semi-annual kWh demand for five years ahead there are still more rooms for the additional demand for energy.

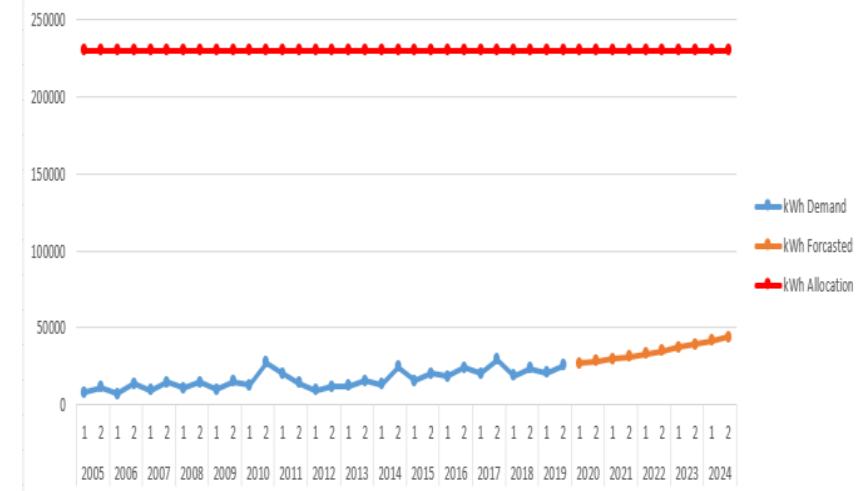

Figure 14: DT 2 kWh Demand, kWh Forecasted and kWh Allocation

DT 3 just like DT 1 it also exceeds the kWh allocation as shown in Figure 15. For the forecasted values it shows that the transformer will become overloaded that will be a disadvantage to its operation.

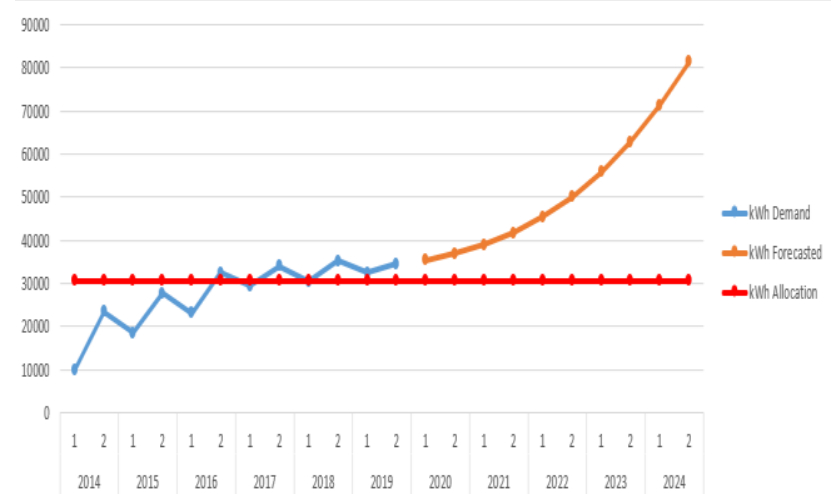

Figure 15: DT 3 kWh Demand, kWh Forecasted and kWh Allocation

\section{CONCLUSION}

The time-series analysis shows that from 2005 to 2019 $\mathrm{kWh}$ Demand of the four transformers installed were increased evidently. DT1 kWh demand per semi-annual increased at a rate of 1.31 percent and its peak kWh demand reached 58114. This case is an overloaded condition that can cause power interruption and can damage the transformer. DT 2 had increased by $1.44 \%$ per semi-annual since this transformer is not overloaded. And even it has a maximum kWh demand of 44523 for the forecasted five (5) years ahead still there is more room for additional loading it can cater. DT 3, on the other hand, increased with a rate of 4.84 percent per semi-annual. In this case, transformer damage may occur on this transformer because it operates in an overloaded condition with a maximum $\mathrm{kWh}$ demand value of 35280

\section{RECOMMENDATIONS}

For recommendations, quantifying and identifying the electric load of building connected is necessary to provide necessary measures to limit or conserve energy to make the transformers maintain normal loading conditions.

Published By:

Blue Eyes Intelligence Engineering

\& Sciences Publication

(C) Copyright: All Rights Reserved

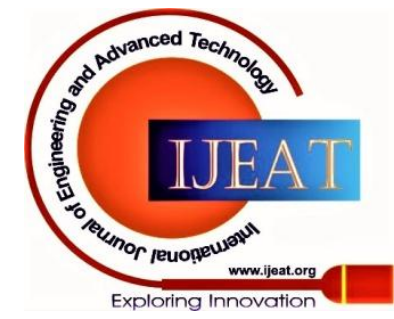




\section{kWh Demand Assessment and Forecasting of a Low Voltage Private Academic Institution}

The two over utilized transformer DT 1 and 3, may be considered to relocate some electric load to the underutilized transformer. For future study, auditing of the connected load may be taken to account to optimize the usage of the transformer.

\section{REFERENCES}

1. Electric Cooperative's Distribution Utility Manual (August 2009) RetrievedonSeptember11,2018,fromhttp://www.gmcdmc.ph/pdf_files _dmc /ECDU\%20Planning\%20Manual\%2010Aug2009.pdf.

2. Ali Arefi, Mahmood-reza Haghifam, Akbar Yavartalab, Javad Olamaei and Hessam Keshtar (2009), Loss Reduction Planning in Electric Distribution Networks of Iran, Retrieved on June 19, 2019fromhttp://0ieeexplore.ieee.org.lib1000.dlsu.edu.ph/stamp/stamp. jsp?tp=\&arnumber $=05876386$.

3. WFu, J McCalley, V Vittal, (2001), Risk Assessment for Transformer Loading, IEEE TRANSACTIONS ON POWER SYSTEMS, VOL. 16, NO. 3, AUGUST 2001.

4. Samesima, M.I., Wilson Resende, J., and Araujo, S.C.N, "Analysis of transformer loss of life driving nonlinear industrial loads by the finite elements approach," IEEE Industry Applications Conference, 1995. Thirtieth IAS Annual Meeting, IAS '95. 8-12 Oct. 1995. Orlando, FL: IEEE, 2175 - 2179.

5. Defu Cai, Wenna Wang, Xianjun Ma, Min Xu, Zhenting He, Zeyang Tang, Chu Zhou, Na Han, Ying Wang , (2018), Analysis of Heavy load and Overload Distribution Transformer in Regional Power Grid

6. P. Georgilakis, Environmental cost of distribution transformer losses, (2011), Elsevier Ltd.

7. E. O'Driscoll and G. E. O’Donnell, "Industrial power and energy metering e a state-of-the-art review," J. Clean. Prod., vol. 41, pp. 53-64, 2013

8. R. Gabo, "Bisu Main Campus Electrical Energy Consumption: Basis for Improvement," vol. 9, no. August, 2012.

9. M. A. Sahagun, A. Tolentino, and R. Gomez Jr., (2018). Assessment and Forecasting of Electric Load Demand of Don Honorio Ventura Technological University, 2018 IEEE, Humanoid, Nanotechnology, Information Technology, Communication and Control, Environment, and Management(HNICEM).

10. M. A. Araneta and et.al., "Cost-Effective Programming of Electric Demand in the University of the Philippines Diliman," vol. 146, no. September, pp. 205-221, 2017

11. H. Tabari, P. Hosseinzadeh Talaee, and P. Willems, "Short-term forecasting of soil temperature using artificial neural network," Meteorol. Appl., vol. 22, no. 3, pp. 576-585, 2015

12. Freedman, Pisani, and Purves, Statistics, 3rd ed. New York: W.W. Norton \& Company, Inc., 1997

13. S. Zheng, Q. Zhong, L. Peng and X. Chai, (2018), "A Simple Method of Residential Electricity Load Forecasting by Improved Bayesian Neural Networks, Mathematical Problems in Engineering, Hindawi, Volume 2018

14. N. Mohamed et al, (2012), "Forecasting Short Term Load Demand Using Multilayer Feed-forward (MLFF) Neural Network Model", Applied Mathematical Sciences, Vol. 6, 2012, no. 108, 5359 - 5368

15. Norizan Mohamed, Maizah Hura Ahmad and Suhartono, 2011 ShortTerm Electricity Load Forecasting. Journal of Sustainability Science and Management, 6(2): 257-266.

\section{AUTHORS PROFILE}

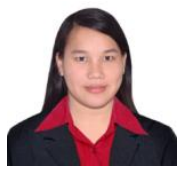

Joy R. Antonio, is the youngest and only daughter and mother of one. She recently moved to Nueva Ecija and finished her degree at Nueva Ecija University of Science and Technology. She passed the board exam titled as registered Electrical Engineer and is currently affiliated as a service contractor in a government institution, the Philippine Rice Research Institute Central Experiment Station located at Maligaya, Science City of Munoz, Nueva Ecija under the Department of Agriculture. The Institution aims to develop high-yielding rice varieties and cost reducing technologies so farmers can produce enough rice, available,

Published By:

Blue Eyes Intelligence Engineering

\& Sciences Publication

(C) Copyright: All Rights Reserved Civil Engineers, Inc.” PICE. accessible for all Filipino's. With her passion, she was recently promoted as an Engineer II to overlook all electrical works (proposed infra projects, on-going infra projects, and repair and maintenance works) for PhilRice Central Experiment Station and its branches nationwide. She is designated as a focal person for the Energy Efficiency and Conservation under PhilRice CES programmed by the Department of Energy.

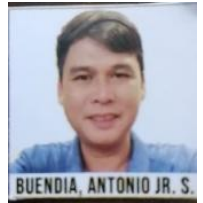

Antonio S. Buendia Jr., The author is an engineer form Nueva Ecija's top electric company. He is happily married to his wife Janet with their daughter Mary Antonette. The author, as a child has only a simple dream, to uplift his family's life from poverty. He and his family doesn't have an easy life. They have to work for the day's meal or else they do not have any to put on the table. And because of the dream to be an engineer, he served as service crew in a fast food chain serving as a part-timer in night and an engineering students during the day. Though a master in multi-tasking, the author is a consistent top student from primary to college where he pursued the Electrical Engineering Course on the top engineering school in Asiathe Nueva Ecija University of Science and Technology. He got his caree service recognition as a licensed electrical engineer and a master electrician during the year 2001, in this sense, he soar higher into his career. He is now currently affiliated with the Tarlac Electric Company as a distribution system technical specialist, he's with the company since the year 2002 With his earnest passion for learning, he continued his graduate studies in the same school he earned his bachelors. And as a curious engineer he began starting doing researches with his colleagues, with their recent work "kWh Demand Assessment and Forecasting of a Low Voltage Private Academic Institution". This is just one of the many researches that he will affiliated with.

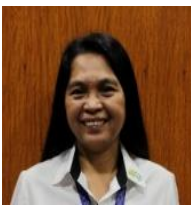

B. Narca, is a Professional License Civil Engineer, a mother of three (3) and presently employed as public servant for more than two (2) decades in one of the reputable government institution in the country. The Philippine Rice Research Institute, Central Experiment Station located at Maligaya, Science City of Munoz, Nueva Ecija under the Department of Agriculture it aims to develop high-yielding rice varieties and cost reducing technologies so farmers can produce enough rice, available, affordable and accessible for all Filipino's. Some awards were received by the author on her unconditional, dedication and hardworking to her tasked, two awards are being received, two times as Outstanding Admin Support Staff and a highest award given by the Head of the Organization or Agency the "Director's Award". The author has a good standing membership for her unduly support in every activity conducted by the organization (National and Provincial Chapter) that gave the members up to date information and technology. The name of the organization is the "Philippine Institute of

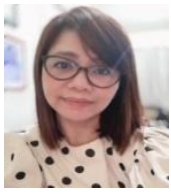

Lorinda E. Pascual, she is a mother of one and a wife. The author is an academe professor by profession. She graduated Bachelor of Science in Electrical Engineering and eventually took up Master in Engineering Education Major in Electrical Engineering and Ph.D. In Mathematics Education. She is currently practicing her profession being Bachelor and Graduate professor at Nueva University of Science and Technology.

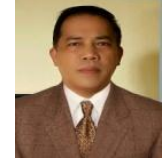

Noel T. Florencondia, is a father and husband. He is a licensed Professional Electrical Engineer practitione since July 22, 1994. He ace to be the top 8 on the PEE licensure exam. He performs to be the Dean of the College of Engineering, Nueva University of Science and Technology from July 2016- January 2021. The author is also an academe Professor IV by profession.

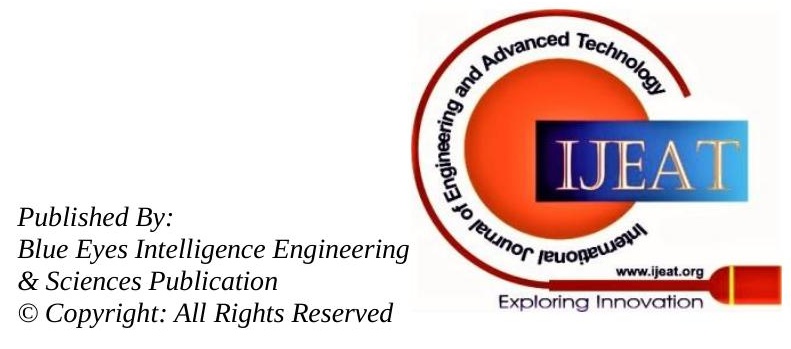

